\title{
Ethnic heritage in Yunnan: contradictions and challenges
}

\author{
Fuquan Yang \\ Yunnan Academy of Social Sciences
}

\section{Introduction}

Yunnan is a province located in the far southwest of China, covering an area of 394,000 $\mathrm{km}^{2}$. Its 4,000 km border adjoins Myanmar in the west, Laos in the south, and Vietnam in the southeast. Yunnan's population is just under 46 million (November 2010), of which 'ethnic minority communities (shaoshu minzu)' comprise roughly one third.

Tourism has become one of the four major industries in Yunnan (the other three being tobacco, mining, and agriculture); more

How to cite this book chapter:

Yang, F 2016 Ethnic heritage in Yunnan: contradictions and challenges. In: Matsuda, A and Mengoni, L E (eds.) Reconsidering Cultural Heritage in East Asia, Pp. 87-102. London: Ubiquity Press. DOI: http://dx.doi. org/10.5334/baz.e. License: CC-BY 4.0 
than 100,000 people were working in the tourism industry in the Lijiang Prefecture of Yunnan in 2010, when the total population was 1.25 million. Tourism based on 'ethnic heritage', in particular, has brought considerable economic benefits to many towns and villages in Yunnan, which used to be a largely poverty-stricken province (Yang 2006, 2007). The growth of tourism, however, has also commodified certain aspects of ethnic cultures, which has generated tensions and contradictions within local communities. This chapter examines these problems and outlines some pilot projects that seek to help resolve them and contribute towards sustainable development. While there are 26 ethnic groups in the province (including the Han), in this chapter I focus on the Naxi and Moso (also known as $\mathrm{Na}$ ), with whom I have had a chance to work on various community-based cultural projects. ${ }^{1}$

\section{Benefits of heritage-based tourism for ethnic minorities in Yunnan}

The most popular heritage-based tourist destination in Yunnan is Lijiang, a prefecture-level city in the northwest part of the province. Lijiang's population is roughly 1.25 million (as of 2010), and the majority of its citizens are Naxi people. Lijiang is famous for its Old Town, which was designated a UNESCO heritage site in 1997 for having been the centre of silk embroidery in the southwest of China in ancient times. It was one of the most important places on the Ancient Caravan Road of Tea and Horses which extended from Yunnan to Sichuan, Tibet, and India. The architecture, culture, and history of Lijiang are quite unique in China.

It was only in the 1990s that the unique value of Lijiang was recognised by the provincial government, which decided to engage in an all-out effort to develop tourism in the city, leading to a 
staggering growth of revenue. Previously, Lijiang had been one of the poorest and most backward areas of the province. In the period from 1978 to 1988, while the annual GDP of Yunnan grew by an average of 9.1 percent, that of Lijiang grew by an average of only 1 percent, making it third from the bottom in the province. The growth in average annual revenue per person in Lijiang ranked fifth from bottom in the province in the same period. By 2010, however, the annual number of tourist visitors to Lijiang had reached 9.1 million, with 611,400 overseas tourists. Annual tourism revenue reached 11.2 billion yuan, or roughly 1.7 billion US dollars, and foreign exchange earnings from tourism in 2010 had reached 1.4 billion yuan (202 million US dollars). In 2010 the city's cultural industries earned 1.5 billion yuan (218 million US dollars), over three times more than they had in 2005, accounting for a rise in GDP from 8.6 percent to 11.8 percent in this period. In 2012, the GDP of Lijiang was 15.0 billion yuan (2.4 billion US dollars), and total tourism revenue reached 11.2 billion yuan (1.8 billion US dollars) (Statistical Bulletin of the National Economic and Social Development in Lijiang n.d.; Yang 2012b).

Lijiang currently has eight travel agencies and 100 tourist information centres (lüyouxingxiangdian, literally 'tourism image stores') nationwide, located in major cities. The 27 travel agencies that previously existed have been integrated into six business groups and today each group manages a particular geographic area with the aim of avoiding excessive competition and friction and creating a safe and orderly market environment.

The following two examples illustrate the success of ethnic tourism in Lijiang. The first is the example of the Dayan Naxi Ancient Music Association located in the Lijiang Old Town. This Association was formed in 1989, with an orchestra comprising teachers, workers, farmers, artisans, and craftsmen, and has since become 
famous for its 'three old things': old music, old musicians, and old musical instruments. By 2007 the orchestra's annual revenue exceeded five million yuan, roughly 650,000 US dollars. Despite the relatively high price of the tickets, 160 yuan (roughly 21 US dollars), the orchestra has large audiences at its daily performances, which have become a regular element of Lijiang's visitor attractions. The orchestra has also performed in many larger cities in China, including Beijing, Shanghai, Tianjin, and Guangzhou, and in over 20 countries overseas. It also performed in the celebrations held in Beijing in 2005 to mark the 60th anniversary of the founding of the United Nations.

The second example is various 'cultural villages' existing in Lijiang which attract tourists with the chance to experience the rural life of the Naxi and Moso people, including village ceremonies, traditional houses and barns, and the opportunity to interact with young and old residents. The most popular of these villages is arguably Luoshui village, located in Lijiang's Nangling County. A collection of highly picturesque wooden Moso homes and guesthouses on the shore of Lake Lugu, to the northwest of Lijiang, this village was at one time extremely poor due to the scant amount of land available for farming. The ethnic tourism that took off in the 1990s brought considerable economic benefits, making it now one of the ten wealthiest villages in Lijiang. A committee made up of residents manages all tourism-related activities in the village, including taking guests to scenic spots by boat and horse. Aiming to avoid unregulated competition and to maintain equity and fairness, the committee has drawn up rules that prohibit or restrict tourism activities that run counter to traditional ways of life. It has even attempted to introduce rules designed to preserve and shore up the matrilineality of its society (Yang 2005). 


\section{Re-energising and protecting ethnic minority culture}

In earlier periods of Chinese history, the majority Chinese often regarded ethnic minority cultures as primitive, backward, and barbaric. This was a view particularly prevalent amongst the ruling classes and urban dwellers, as attested by many accounts in official records, especially those written in the Qing dynasty (1644-1912).

Ethnic heritage-based tourism initiated in Yunnan in the 1990s has helped build wider appreciation of ethnic minority cultures in China, and at the same time has helped these communities nurture pride in their own heritage. The integration of ethnic cultures and tourism has clearly increased the awareness of the value of ethnic heritage in Yunnan amongst people in government and business, as well as artist groups. Whether ethnic cultures are perceived as a draw for tourism or valuable in their own right, this movement has clearly contributed to a flourishing of indigenous cultures.

There is now a particular interest in the ancient Dongba culture associated with the Naxi people, the most famous examples of which include religious manuscripts, music, and painting. Dongba culture has today become one of the major tourist attractions in rural and urban areas of Yunnan (and also Sichuan province to the north). Today, one can find Dongba calligraphy or Dongba-style paintings hanging in local houses, or lines or words from Dongba poetry inscribed on the pillars of front gates of various buildings.

In Yunnan some grand-scale ethnic dance performances have emerged from the confluence of tourism and ethnic cultures. One of such performances is called 'Dynamic Yunnan' (Yunnan 
Yingxiang) and features the dancer and choreographer Yang Liping, a member of the Bai ethnic community. Another performance, entitled 'Impression Lijiang' (Yinxiang Lijiang) and first played in 2006, is an open-air folk musical directed by the internationally renowned film director Zhang Yimou and staged at the foot of Yulong Xueshan, a mountain massif near Lijiang. Both performances draw strongly on ethnic traditions, and the majority of the performers are from ethnic minority communities.

Both the national and provincial governments have enacted regulations to protect and promote ethnic heritage. In 2000, the national Regulations on the Protection of Traditional Folk Culture in Yunnan was established, which was the first of a kind in China. In 2006 the Standing Committee of the National People's Congress enacted provincial level regulations, which are known collectively as the Regulations on the Protection of Dongba Cultures and designed to protect Naxi ethnic heritage. Meanwhile, the Yunnan government initiated a census on folk cultures in Yunnan and their intangible heritage between 2000 and 2002 with funding from the Ford Foundation. These legal and administrative frameworks have facilitated the conservation of ethnic heritage in Yunnan (Yang 2010).

The increased awareness of the value of cultural heritage in Yunnan has also led the national government to promote it internationally. As stated, Lijiang Old Town was inscribed on UNESCO's World Heritage List in 1997. In addition, the Ancient Naxi Dongba Pictographic Manuscripts were inscribed on UNESCO's World Memory List in 2003, and the Cultural Landscape of Honghe Hani Rice Terraces in Southern Yunnan - an area of 16,603 ha of rice terraces developed on mountain slopes and attributed to the Hani people in Yuanyang County - was registered on the World Heritage List in 2013. 


\section{Problems in the conservation of ethnic heritage}

While tourism has brought significant economic prosperity to Yunnan since the mid-1990s, the penetration of a commoditybased economy has generated tensions and contradictions. One of the consequences of commercialisation in Lijiang is that many local residents, particularly those in the Old Town, are increasingly renting out their homes and staring to live elsewhere, drawn by the profit that can be earned by leasing properties and also by the wish to avoid the crowds and noise (Yang 2004). Most of the new residents arrive to run businesses or simply for leisure. Often they are not interested in traditional Naxi culture, particularly in learning the Naxi language.

This change marks a real difference from how Lijiang has been historically. The city has seen waves of migration from other regions of China for centuries; a 1950 survey of the 156 surnames of residents in Lijiang Old Town revealed how immigrants from many different parts of China came to live in the town, especially during the Ming (1368-1644) and Qing Dynasties (1644-1912). In the past, however, these incoming groups tended to blend in with the Naxi people and their cultures (Yang 2012b).

The lack of integration of currently incoming groups into the local culture creates an alarming situation, as Naxi tradition seems in fact to be in decline. By 2003, the last three great Dongba master priests, who were living repositories of knowledge on Dongba culture - particularly the highly complex Dongba writing system which is said to take at least ten years to master - had died, leaving no comparable successors. In the 1980s, the Yunnan government started funding the translation and publication of 1,000 Naxi manuscripts, and nearly 20 Dongba priests and 10 scholars worked on this endeavour for over 20 years. Little attention was, 
however, directed to the training of younger priests, and today there are very few qualified Dongba priests who are able to translate various Dongba manuscripts housed in museums and university libraries around the world as skilfully as their former master priests. How to train Dongba master priests is a crucial question for the Naxi people, as it involves the passing of Dongba cultural, intellectual, and religious heritage on to future generations.

Surely it would be impossible to force Naxi residents to stay in Lijiang Old Town. It would be equally impossible to force incoming residents to learn about the local culture and to conserve the Naxi language. The changing composition of the current population in Lijiang - and indeed throughout Yunnan province - is gradually affecting traditional customs and practices; it clearly endangers the authenticity and vitality of Naxi culture as a whole.

Traditional Moso culture is similarly under threat. One of the most interesting features of the Moso people is the strongly matrilineal nature of their society and the related 'visiting relations' system (zou hun in Chinese; ti se se in the Moso language), in which sexual partners do not live in the same household. The majority of the Moso people wish to conserve their matrilineal tradition, and have even sought to have it registered on UNESCO's List of Intangible Cultural Heritage. However, conservation is likely to prove difficult with the seemingly unstoppable march of modernisation; marriage is gaining in popularity, and today the right to marry the person one chooses is naturally seen as a human right. Young Moso people are increasingly going farther afield to find work in urban areas, which is inevitably affecting traditional customs. Similarly, people from other communities and areas move into Moso villages to run commercial enterprises, with an inevitable effect on indigenous kinship. Villages like Luoshui and Lige, the main attraction of which lies in the fact that they are Moso 
villages, are following the example of Lijiang Old Town. More and more local people now rent their family-run inns to people from outside the villages, instead of running them themselves.

Luoshui village has attempted to preserve the traditional organisation of its large matrilineal families through a series of measures, including the so-called 'one fire place, one person' policy. Aiming to prevent the weakening of local customs, the policy limits the number of persons per family who are allowed to take part in village-run tourism activities. Despite such efforts, there are growing numbers of families where partners live under the same roof and run along 'nuclear' lines.

Another recent phenomenon is the increase of young people of ethnic minority background from rural areas, particularly women, who go to urban areas in search of work. This has given rise to serious problems for the conservation and continuation of village traditions. As the composition of rural society changes, with more elderly people and fewer women left behind, it is becoming difficult to preserve person-to-person transmission of intangible cultural heritage. This is symptomatic of the broader challenge of conserving intangible cultural heritage in China today, where modernization and urbanization are proceeding apace.

Erosion of traditional value systems and lifestyles, loss of intangible cultural heritage, and commodification of religion and culture are by-products of economic development brought by tourism. Tangible cultural heritage, particularly architecture, has also been affected. In Lijiang Old Town, for example, some new residents who are renting Naxi houses for commercial purposes have replaced their architectural features with those of the traditional Han style, assuming that it is acceptable because both architectural features are 'traditional'. In other cases, local people have replaced traditional buildings with modern ones, influenced by urban styles seen 
on television. The case in point is the five traditional villages in the Xishuangbanna autonomous region in southern Yunnan, which had a tourist attraction rating of $4 \mathrm{~A}$ according to the China National Tourism Standard Association's standards (the highest being 5A). Once the local villagers experienced the economic benefits brought by tourism development, they started building Western-style villas alongside their traditional bamboo dwellings, which immediately triggered tourist complaints and criticisms (Yang 2013).

This last example highlights the problems inherent in the conservation of traditional buildings in tourist villages: one might consider that Western-style buildings incongruous with village traditions should ideally be avoided, but it would also be unfair to ask villagers to keep living in traditional bamboo buildings without proper sanitary facilities just for the sake of attracting tourists. Thought must be given to suitable ways to refurbish the traditional village architecture, so that living conditions can be improved inside buildings without affecting their outside appearance. Researchers, architects, and planners also have to think in more far-reaching ways about encouraging an appreciation and understanding of the cultural and spiritual value of traditional architecture among residents (Yang 2010).

All this points to an urgent need for the development of sustainable forms of ethnic tourism, which aims for the conservation of the vitality of ethnic cultures. For this to happen, the active inclusion of ethnic minorities is vital.

\section{Pilot projects for cultural heritage conservation in Lijiang}

I have led and participated in a number of pilot projects designed to explore best practice for the conservation of ethnic heritage in 
Yunnan, especially the heritage of the Naxi Dongba culture. These projects were concerned with: the training of future Dongba priests; the training of young practitioners of traditional music; the promotion of young people's interest in indigenous knowledge and traditional folk customs; and the training of women in traditional handicrafts, particularly embroidery.

The first of these projects, aimed at training Dongba priests, ran from 2000 to 2003 in Lijiang, with the financial support of the Beijing Office of the Ford Foundation. The project group selected eight students from several villages that have particularly rich Dongba traditions; some of the students were sons and grandsons of Dongba priests. Experienced Dongba masters then offered training to the students in accordance with traditional training methods, with the assistance of researchers at the Dongba Culture Research Institute. The Dongba masters and the students lived together during the training. The students were required to learn manuscripts by heart and to study Dongba rituals, writings, singing, and dancing, and how to construct the materials used in rituals such as facial masks, painted wooden tablets, and ritual offerings. They also had to undertake regular and rigorous examinations. At certain intervals they then went back to their villages for several months to practice what they had learnt and to acquire more folk knowledge from their village elders. This project proved quite successful, and many of the students have since become respected priests in Lijiang.

The second project, which ran from 2001 to 2004, aimed at encouraging young musicians to learn how to perform one of the two surviving forms of traditional music, Baisha Xiyue, which is a kind of classical orchestral music dating from the Yuan Dynasty (1271-1368), involving flutes, shawms, lutes, and zithers. Baisha Xiyue is said to represent a merging of Mongol palace music and 
Naxi music. The story goes that in 1253 Kublai Han presented the Naxi ruler Mailiang with an orchestra when Mailiang welcomed him at Fengke. When the pilot project was initiated, there were very few surviving musicians who could play this music. The project team worked with the master musician He Maogen, an officially recognised descendent of a long line of Baisha Xiyue musicians, who had also trained his son He Linyi and his nephew over many years so that both could become outstanding musicians.

The third project, which was supported by the Beijing Office of the Ford Foundation, had as its objective the teaching of local knowledge relating to Naxi cultural heritage to primary school children in rural areas. The idea underlying the project was to promote the transfer of basic knowledge of tangible and intangible cultural heritage from childhood. As its first site the project team selected the Baisha Primary School in Baisha Town, Yulong County. The training was based on a participatory methodology; teachers, students and their parents, and project researchers all took part. The stakeholders in the project, including researchers, government officials, villagers, school teachers, and students and their parents, discussed together what kind of local knowledge one should learn and what methods should be used for that purpose. The project participants sought to introduce experimental education and link it to the government plan for the promotion and education of local knowledge. We carried out fieldwork together with teachers and students to investigate community resources, including landscape, forests, rivers, agriculture, history, and folklore, conducted interviews with local elders, craftsmen, herb healers, and other community members, and invited folk singers and elders to give lectures to the students. Thereafter, 
the project group compiled and edited a textbook to be used by students and teachers in the community. We also selected and used students' paintings in the Dongba pictographic style in another textbook edited by the Ministry of Education, which was designed to teach local knowledge. Similar projects were also carried out in primary schools, the intake of which comprised the children of Tibetan and Dai ethic minority groups. Here again, the participants included teachers and students, local educational officers, and scholars of the Yunnan Academy of Social Sciences.

The fourth project was designed to counteract the decline in the knowledge of handicrafts in rural areas, particularly embroidery. My team carried out a four-year project in Baihua, a Naxi village in Huangshan Township, Lijiang, in order to train ethnic minority women in traditional handicrafts, with the support of Misereor, a Catholic charitable foundation funded by the German Federal Ministry for Economic Cooperation and Development. Trained by knowledgeable elders, more than 15 women of various communities, including the Naxi, Moso, Lisu, Tibetan, and Bai, learned how to produce attractive handicrafts involving weaving, embroidery, and dyeing with traditional natural materials. They earned enough money to improve their living conditions in only a few years, and are now teaching their skills to other young women.

This last project also provided an insight into how to combine the production of traditional handicrafts with the demands of the modern market. The key seems to lie in maintaining distinctive local characteristics. Innovation is possible in terms of deciding what kind of items to be produced - for example, silk scarves which tend to have an appeal to young people - but tradition can 
be maintained in the use of the patterns and designs distinct to the locality (Yang 2012a).

\section{Conclusion}

The current state of cultural heritage varies significantly from one ethnic community to another in Yunnan province. Within the wider climate of social change, some communities have developed heritage-based tourism rather successfully. The orchestra of the Dayan Naxi Ancient Music Association, for example, has greatly benefited from tourism development. At the same time, however, the changing social and economic conditions are threatening the heritage of other ethnic communities. For instance, some folk music in rural areas is in decline, especially music that involves improvisation. Also, despite our best efforts, many aspects of knowledge of Dongba culture, in particular writing and religious rituals, are gradually disappearing. The conservation of such forms of living cultural heritage poses a big challenge as it requires large amounts of time, energy, and commitment.

Notwithstanding the considerable attention now being directed to the conservation of ethnic cultural heritage in Yunnan, both on provincial and national levels, many problems still remain. Balancing between gaining economic benefits and maintaining the core value of cultural heritage is a particularly challenging task. Cultural heritage is an important attraction for tourism that can bring much needed alleviation to poverty-stricken areas, but it is also a sensitive asset that can be damaged by the same tourism. Achieving the sustainable conservation of cultural heritage is a pressing and important issue in Yunnan. In order to make informed judgement about how to achieve such sustainable 
conservation, more action research based on pilot projects needs to be carried out.

\section{Note}

${ }^{1}$ Although the Chinese government categorises the Naxi and Moso peoples as being in the same ethnic minority, researchers generally agree that they are culturally distinct. While broadly sharing the same historic origin, the Naxi and Moso cultures have developed differently over time. The chief distinguishing characteristics of the Moso people include the strongly matriarchal and matrilineal aspects of their society.

\section{References}

Statistical Bulletin of the National Economic and Social Development in Lijiang (n.d.) http://www.lijiang.cn/ (accessed on 1 September 2015).

Yang F 2004 Some problems of Tourism Development in Yunnan. Social Sciences in Yunnan, 3.

Yang F 2005 A Plan for Lijiang: Tourism and Culture. Beijing: Ethnic Nationalities Press (Minzu Press).

Yang F 2006 The Reports of Yunnan Tourism Development (Annual Blue Books), 2005-2006. Kunming: Yunnan University Press.

Yang F 2007 The Reports of Yunnan Tourism Development (Annual Blue Books), 2006-2007. Kunming: Yunnan University Press.

Yang F 2010 Conservation and Development of Famous Towns and Villages of Yunnan. Beijing: Zhongguo Shuji Chubanshe (China Book Publishers).

Yang F 2012a. The practice of mentorship of ethnic folk cultural heritage and challenges in Lijiang. In The Collection of Papers on the latest development and Practice of Applied Anthropology in China. July. Beijing: Ethnic Nationalities Press (Minzu Press).

Yang F 2012b A Brief History of Contemporary Naxi. Kumming: Yunnan People's Publishing House. 
102 Reconsidering Cultural Heritage in East Asia

Yang F 2013 Seeking the Balance between Ethnic Cultural Resources and Development of Cultural Industry. Making Yunnan as an Example. Journal of Minzu University of China (Philosophy and Social Sciences Edition), 2. 